2017-08

\title{
Antonio Gramsci on intellectual thought Challenging nursing
}

goodman, benny

http://hdl.handle.net/10026.1/9653

10.1016/j.nedt.2017.02.023

Nurse Education Today

Elsevier BV

All content in PEARL is protected by copyright law. Author manuscripts are made available in accordance with publisher policies. Please cite only the published version using the details provided on the item record or document. In the absence of an open licence (e.g. Creative Commons), permissions for further reuse of content should be sought from the publisher or author. 


\section{Antonio Gramsci on intellectual thought - challenging nursing.}

Antonio Gramsci (1891-1937), leader of the Italian Communist party, was arrested and imprisoned by the fascist regime in 1926 and died in the Quisisana clinic in Rome in 1937, aged 47 . His pre prison work and his 'prison notebooks' have hugely contributed to the examination and development of political philosophy and intellectual thought. Among the ideas he developed are the role of the intellectual in culture and politics and the concept of hegemony. The prosecutor at his trial was acutely aware of his intellectual abilities, and thus threat, and stated:

"We must prevent this brain from functioning for twenty years." (Buttigeig 2011 p16).

Gramsci found himself in a concrete prison not of his own choosing, put there by the strategic action of powerful others. Nurses might find themselves in an abstract prison of the mind put there by their own reason, their lifeworld colonised by the systematic distorted communication of the strategic action of powerful others.

This is all a world away from the daily work of nursing, and so at first pass may appear of interest only to the likes of critical social scientists or historians of political thought. Yet, reading Gramsci opens up a discussion on what being an intellectual might mean and of how power is exercised and maintained, concepts applicable to health education. Most nurses going about their clinical work will not be vexed by such questions and it might be the case that academic nurses will not be either. That could be a mistake given the current context outlined by Streek (2016) of global challenges to social order which have current and future impacts on health and health care delivery.

That context is variously called late modernity, post modernity, post-industrial, disorganised, financial, rentier, or neoliberal capitalism. Wolfgang Streeck (2016) echoing Gramsci, suggests this context is actually a post-capitalist interregnum in which the old system is dying but a new social order cannot yet be born. Streeck calls the current order one of multimorbidity, climate change being one of many frailties as we head towards social entropy, radical uncertainty and indeterminancy. Streeck argues that the current context is anchored in a variety of interconnected developments including rising social inequality and populist nationalism and the spectre of fascism and isolationism in the US. To that we could add continuing health inequalities, the potential for ecosystem collapse and the emergence of disruptive technologies: Automation, Artificial Intelligence and Digitalisation which could impact on medical and nursing care.

There are countervailing voices such as Joseph Norberg (on the possibility and actuality of progress), Daniel Ben-Ami (on growth based capitalism to solve ecological problems) and Stephen Pinker (on reducing levels of global violence) who paint more positive pictures. Add of course the voices of politicians who promise to 'Make America Great Again', to create "A country that works for everyone' or establish 'Russia as a Normal Great Power' or to regain 'primacy in South East Asia after a century of humiliation'. The picture now is one of complexity, tension, dynamics and unpredictability. 
None of this directly concerns most UK nurses who work with individuals who are ill, distressed, living with long term conditions, or dying in hospital and at home. And yet many nurses are also involved in public health basing their approaches mainly in general health management, health education and health promotion (Kemppainen, Tossavainen and Turunen 2012). Their training and education focuses on instrumental competency based knowledge and skill acquisition but it may lack critical enquiry into the socio-political context in which they work. Gramsci's approach to intellectual enquiry could provide a blueprint for alternative or complementary critical nurse education that has to consider wider sociopolitical determinants of health, the sort of developments that Streeck outlines.

\section{Gramsci's thinking}

We get an insight into how Gramsci's brain functioned from a letter he wrote in 1929 to the wife of a comrade who also was in prison for 'anti-fascist' activity. The context is that of how to study while in prison. The prison referred to, of course, had concrete existence. However, if we consider that today nurses may imprison themselves within the conceptual walls of stultifying paradigms that block freedom of critical thought, for example biomedical empiricism, his thoughts on reflection and analysis might be useful. The letter predates $\mathrm{C}$ Wright Mills' 1959 chapter on intellectual craftsmanship, a reading of which shows some commonality in approach and is an alternative to the metrics used today in our research excellence framework assessments. One wonders if Gramsci was writing today, would he secure tenure in some contemporary Universities.

He wrote in the letter that one must abandon, in the prison context, the 'scholastic mentality' and banish the thought of pursuing a regular and in depth course of study. Along with Wright Mills who later wrote about avoiding empirical work if he could help it as it was merely about sorting out facts and disagreements about facts, this statement appears to be counter intuitive until one considers that a goal of intellectual life could be about criticality, understanding philosophy, self, culture, history, politics and society. Again put this way, many nurses may well eschew intellectual enquiry as irrelevant to their daily practice.

Gramsci urged language learning as rewarding, but more interestingly is his outlook on the relative paucity of texts in prison libraries. He argued that a political prisoner must extract "blood from stones" (Buttigeig 2011 p15). The paucity of books in prison was of course a function of the external constraints imposed by the regime. The 'paucity of books' available to students today may be a result not of external concrete constraints but of internal self imposed constraints as to what counts as proper reading for a degree in Nursing. Gramsci experienced a concrete prison of walls imposed by the fascist regime. We might experience a 'prison of the mind' constructed by dominant cultural ideas (hegemony) imposed by ourselves upon ourselves through the process of normative governmentality. Gramsci argued for 'extracting blood from stones', the stones being whatever he could get. 
To get the most of the books available to him, often popular novels, Gramsci adopted the following viewpoint:

"Why is this always the most read and most published literature?"

"What needs does it satisfy?"

"What aspirations does it respond to?"

"What sentiments and views are represented in these awful books that have such broad appeal?"

For student nurses, these questions could be applied to many of the texts, for example the professional body's literature, that they read to assist with the development of critical thinking. Critique could be emancipatory but in actuality reading ends up in uncritical acceptance. I'm not talking about appraising and critiquing research evidence or engaging in critical analysis of for example leadership theories in nursing. Criticality is lacking in the socio-political and power domain and also of reflexivity.

An example of the lack of such criticality is the almost universal acceptance of the UK's Nursing and Midwifery Council's revalidation process. The requirement is for nurses to renew their registration every three years by following the process outlined by the NMC. The surface reason for revalidation is that it "promotes greater professionalism among nurses and midwives and also improves the quality of care that patients receive by encouraging reflection on practice against the revised code'. If we apply Gramsci's questions above to the texts on revalidation put out by the NMC, a possibility arises that we just might make alternative and critical analyses of just such banal statements in official publications.

"Why is the NMC always the most read and most published literature on professional behaviour?" Because of its statutory position as the regulator to protect the public. Because Nurse educators use it as the basis for their teaching. Because the NMC has the power to discipline nurses.....

"What needs does it satisfy?" Neophyte nurses, especially, need guidance on professional behaviour and standards and don't have the time, or resources or educational preparation to consider this in an in depth way. NMC guidance provides the generally widely accepted standard......

"What aspirations does it respond to?" To keep one's registration and to bolster one's subject position as 'safe practitioner'. It is also a mechanism of neoliberal control focusing on the individual rather than the structure of health care delivery and thus satisfies certain stakeholders that 'something is being done' to uphold care standards. 
"What sentiments and views are represented in these awful books that have such broad appeal?" The sentiment of nursing as 'character based moral work', of nurses as 'caregivers', as self sacrificial angels who always cope......

The answers to the 4 questions of course are myriad and those above are merely some examples requiring further reflection, reflexivity and criticism. The lack of critique of the $\mathrm{NMC}$ on revalidation illustrates 'normative governmentality', in that nurses and midwives, and perhaps more interestingly nursing academics, have internalised certain norms, values and assumptions that prevent them from seeing anything other than the official line. This could be an example of what Furedi (2006) refers to as philistinism underpinned by instrumentalism in higher education, in which academics become educational technocrats rather than what Gramsci refers to as organic intellectuals.

Intellectuals are those with broad reading, vision and a concern for public issues. Graham Scambler argues intellectuals are not only engaged in the public sphere but do so around an identifiable moral or political position. A question arises about the degree nurses and midwives are, or wish to be, engaged in moral and political questions, the degree to which they can engage in communicative action free from systematic distorted communication.

The questioning of texts exemplifies the Gramscian notion of critical enquiry and action and allows us to consider such questions as, for example, what counts as research in contemporary nursing faculties. The answer to that is political in that it frames what nurse academics study, write about and publish, and it frames what students of nursing count as valid knowledge. If we apply those questions to the published outputs of contemporary nursing scholarship what answers would we get? For example, does a high $\mathrm{h}$ index always indicate intellectual rigour or criticality? Given the wider determinants of health, which include the social, political and ecological, it could be suggested that health care professionals would be aided in their understanding of health and illness, and hence what to do about it, by critical enquiry that goes beyond accepted epistemologies.

Nursing students have been told to be critical thinkers and many University curricula claim to foster such thought. Texts are not to be accepted at face value, and that we should examine assumptions and viewpoints of writers. This should go beyond for example appraising research literature for methodological rigour. Should we also appraise the metaparadigms and epistemological assumptions of 'acceptable' and 'REFable' nursing research? Should we ask what degree does contemporary scholarship in nursing reflect the sort of intellectual enquiry that Gramsci and Wright Mills advocate? In a world increasingly characterised by forces that threaten to disrupt stability and global order in ways that could be catastrophic to human health, are we preparing nurses to face that?

Gramsci died far too soon, and 'without honour in his own country'. Whether he considered his life a failure in that fascism still held power, nonetheless he provides a template for thinking, studying and critique in difficult circumstances. He had a vision, he was an intellectual, he had a political purpose. Whether academic nurses in the $21^{\text {st }}$ century find this inspiring or irrelevant may depend on what vision we have for nursing praxis for the future. 
Buttigeig J (2011) in Gramsci A (1975) Prison Notebooks. Volume 1 Edited by Einaudi G. Columbia University Press. New York.

Furedi F (2006) Where have all the intellectuals gone? Confronting $21^{\text {st }}$ Century Philistinism. Continuum.

Gramsci A. (1975) Prison Notebooks. Vos 1-3. Edited by Einaudi G. Columbia University Books. New York.

Kemppainen V, Tossavainen K, and Turunen H. (2012) Nurses' roles in health promotion practice: an integrative review. Health Promotion 28(4):490-501.

Scambler G (2013) What is an intellectual? http://www.grahamscambler.com/what-is-anintellectual-2/ accessed $7^{\text {th }}$ February 2017

Streeck W (2016) The post-capitalist interregnum: the old system is dying, but a new social order cannot yet be born. Juncture 23 (2): 68-77

Wright Mills C (1959) The Sociological Imagination. Oxford University Press. Oxford. 